\title{
Chronic Extradural Hematomas: An Illustrative Case Report and Review of Literature
}

\author{
Rajeev Sharma ${ }^{1}$ Satish Kumar Verma ${ }^{1}$ Sumit Sinha ${ }^{1}$ \\ ${ }^{1}$ Department of Neurosurgery, All India Institute of Medical Sciences, \\ New Delhi, India \\ Address for correspondence Rajeev Sharma, MCh, Department of \\ Neurosurgery, All India Institute of Medical Sciences, New Delhi \\ Indian J Neurosurg 2016;5:163-171. \\ 110029, India (e-mail: rajufbd79@rediffmail.com).
}

\begin{abstract}
Keywords

- chronic extradural hematoma

- head injury

- venous sinus injury

With the easy availability of computed tomography scanning, the majority of large extradural hematomas are identified and evacuated early. Hence, a large chronic extradural hematoma (CEDH) is rarely encountered in current clinical practice. The authors describe an interesting case of a large bifrontal CEDH associated with superior sagittal sinus injury in a 32-year-old man. We also present a review of 43 cases available in the literature, and discuss various concepts of classification of CEDHs and their management.
\end{abstract}

\section{Introduction}

Extradural hematoma (EDH) identified more than 14 days after head injury is classified as a chronic extradural hematoma (CEDH). ${ }^{1}$ A CEDH is an elusive lesion ${ }^{2}$ and is rarely encountered in current clinical practice. This article describes an unusual case of a large bifrontal CEDH associated with superior sagittal sinus injury. A concise review of cases available in literature in the post-computed tomography (CT) era is also presented as an update.

\section{Case Report}

A 32-year-old man was admitted to our trauma center after being in a road accident 35 days back with persistent mild to moderate headache since the time of injury. At the time of injury, his clinical examination at another hospital was normal and there were no signs of any external injury or comorbidity. Noncontrast computerized tomography of the head on day 1 (-Fig. 1A) showed a large acute bifrontal extradural hematoma. There was no overlying bone fracture. Day 3 magnetic resonance imaging (MRI) of the brain (-Fig. 2A-F) showed an $8.9 \times 5.0 \times 4.4 \mathrm{~cm}$ (approx. 100 $\mathrm{mL}$ ) sized acute bifrontal extradural hematoma. The anterior one-third of the superior sagittal sinus could not be visualized on MR venography. The circle of Willis was normal on MR angiography and there was no subarachnoid hemorrhage.
Serial CT head scans ( - Fig. 1B, C) showed progressive decline in density of the hematoma without any change in size. There was no history of vomiting, seizures, unconsciousness, cognitive decline, or sensory-motor deficits. Except having bilateral papilledema, his clinical examination was normal at the time of admission in our trauma center. He underwent bifrontal craniotomy and complete evacuation of partially liquefied large bifrontal extradural hematoma on 37th day after injury. There was no active bleeding from superior sagittal sinus. Outer hematoma membrane beneath the bone flap was excised, but inner hematoma membrane densely adherent to the outer surface of dura mater was left undisturbed ( - Fig. 3A-C). Multiple dural hitches were taken before replacing the bone flap. Postoperative recovery was uneventful and CT head (-Fig. 3D-F) showed small right frontal subdural hygroma. Patient has been asymptomatic at 4-months follow-up.

\section{Materials and Methods}

We conducted a computer-based search (PubMed, Google) for the published articles available in literature describing patients with a diagnosis of CEDH using the following keywords: chronic, extradural hematoma, venous sinus injury. Extradural hematomas operated/diagnosed 14 days or more after head injury were defined as CEDHs in our study. We excluded extradural hematoma cases operated $<14$ days received

February 29, 2016 accepted after revision

May 31, 2016

published online

December 5, 2016
Dol http://dx.doi.org/

10.1055/s-0036-1588038. ISSN 2277-954X. (c) 2016 Neurological Surgeons' Society of India
License terms

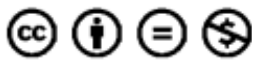



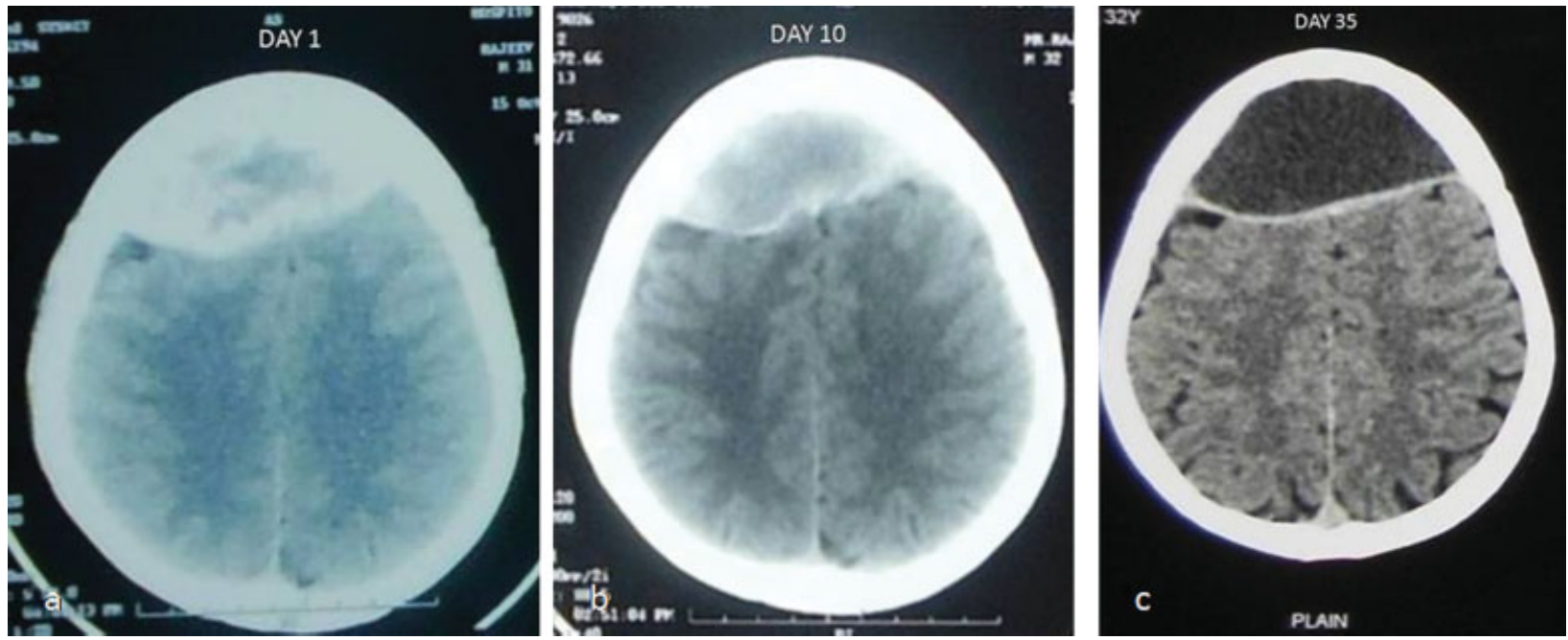

Fig. 1 Computed tomography of head (A) at day 1 showing a large bifrontal extradural hematoma, (B, C) at day 10 and day 35 respectively, showing progressive resolution of a large bifrontal extradural hematoma.
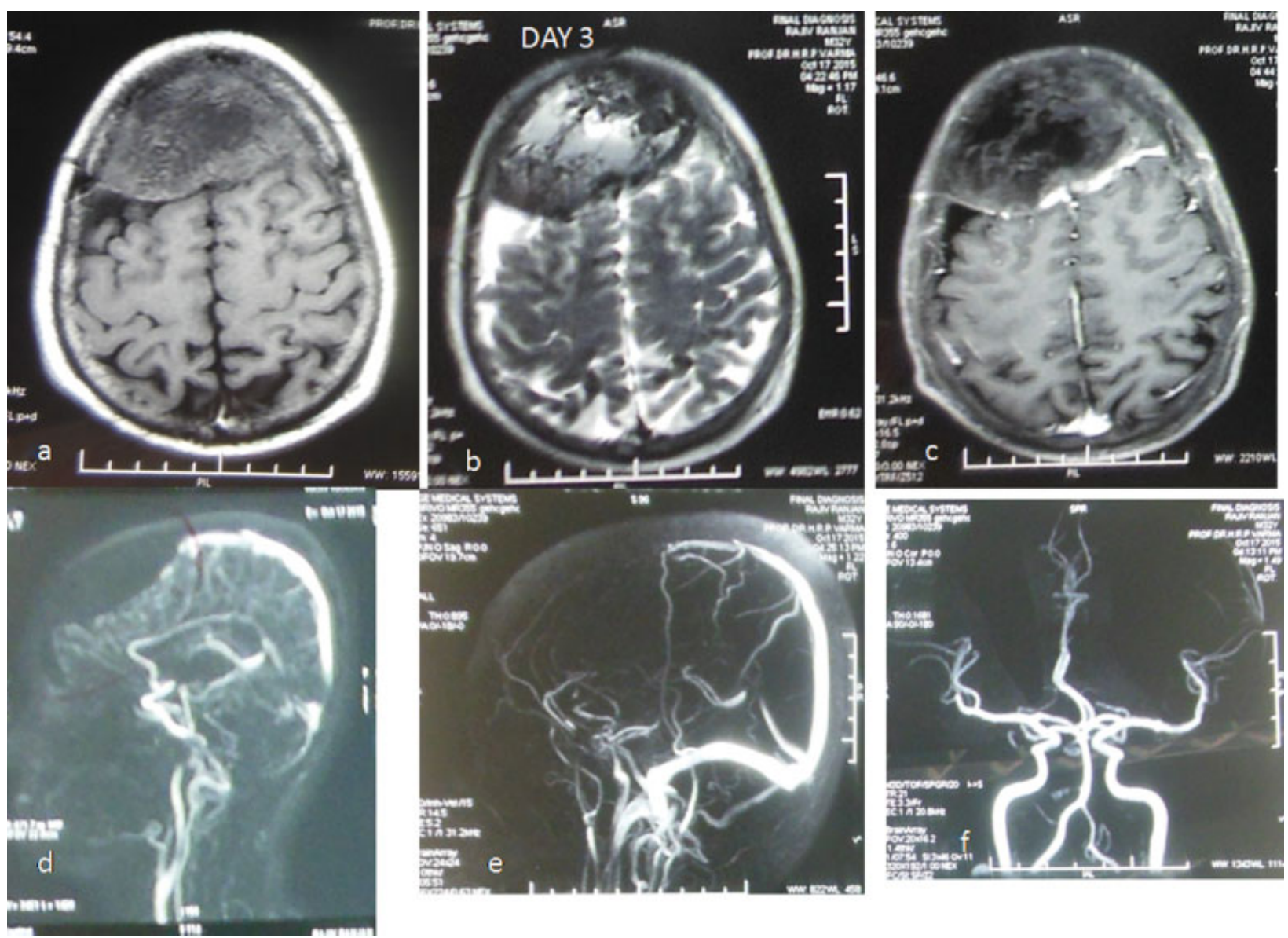

Fig. 2 Magnetic resonance imaging of brain showing $8.9 \times 5.0 \times 4.4 \mathrm{~cm}$ sized acute bifrontal $(R>L)$ extradural hematoma $(A)$ isointense on T1, (B) heterointense on T2, (C) no active bleeding on contrast, (D, E) magnetic resonance venography showing nonvisualization of anterior one-third of the superior sagittal sinus, (F) magnetic resonance angiography showing circle of Willis was normal.

after head injury. CEDH patients operated without CT (in preCT era) were also excluded. From each publication, we excerpted the following data: age, sex, mode of presentation, sensorium, injury to operation/diagnosis interval, association with overlying calvarial fracture, location, density and source of hematoma, management, and outcome. When there was no information regarding a certain parameter, we recorded the data as "not available"; and the case in question was excluded from the denominator for that particular parameter only in the analysis. 

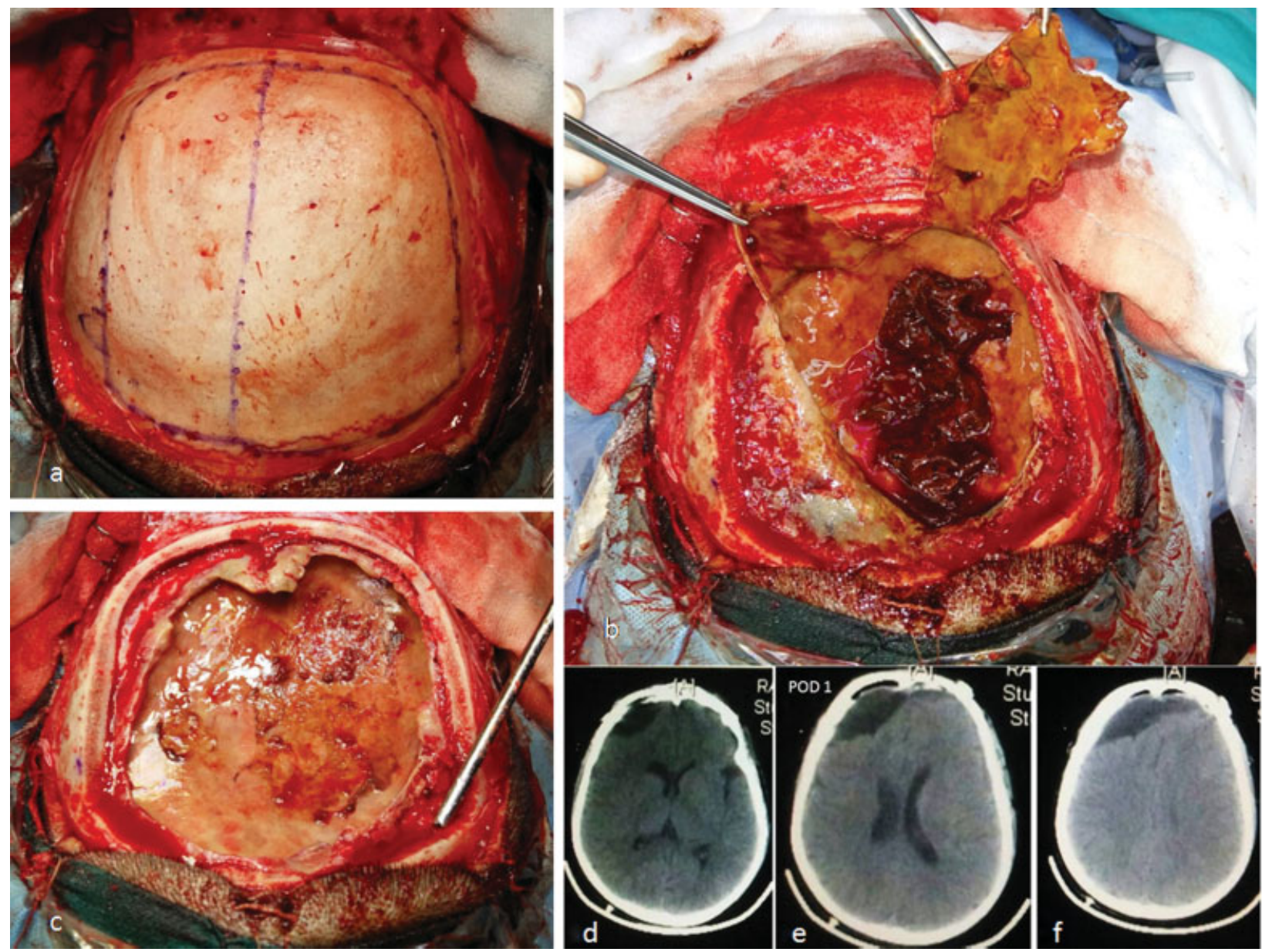

Fig. 3 Preoperative photograph showing (A) bifrontal bone before craniotomy: no fracture, (B) outer (held by forceps) and inner hematoma membranes and partially liquefied clot lying over dura mater seen after bifrontal craniotomy, (C) after excision of the outer hematoma membrane; (D-F) postoperative computed tomography of the head showing small right frontal subdural hygroma.

\section{Results}

Out of 37 published articles collected using these keywords, only 43 patients (including our patient) from 23 published articles met our inclusion criteria (-Table 1 ). Literature review showed many case reports of calcified/ossified CEDH in children. Fourteen studies were not included in the analysis (-Table 2).

We included only 6 out of 17 patients (angiography, 11; CT, 6) from Zuccarello et $\mathrm{al}^{3}$ study, as CT scan was performed in only 6 of them. We included only 1 out of 3 patients from Handa et $\mathrm{al}^{4}$ study, as the remaining 2 patients were operated in $<14$ days after injury. We included only 1 out of 7 patients from Hirsh et $\mathrm{al}^{5}$ study, as the remaining 6 patients were operated in $<14$ days after injury. We included only 1 out of 3 patients from Tochio et $\mathrm{al}^{6}$ study, as the remaining 2 patients were diagnosed within $<14$ days after injury. Tochio et $\mathrm{al}^{6}$ managed all 3 of them conservatively. We could include only 6 out of 8 patients from Tatagiba et $\mathrm{al}^{7}$ study, as the remaining 2 patients were operated on day 12 after injury. Out of 3 patients from Illingworth et $\mathrm{al}^{8}$ study, only 1 patient who presented with headache 15 days after injury was included in the analysis. This patient was diagnosed to have right parietal EDH, ascertained by a CT scan 15 days after injury, and was managed conservatively. The remaining 2 patients were diagnosed within 4 days of injury, hence excluded from analysis. Serial scans on follow-up showed complete resolution of hematoma in all these 3 patients managed conservatively.

Out of 30 patients analyzed by Pozzati et al, ${ }^{9}$ there were 10 patients who were operated $>14$ days after injury. But CT was done in only 4 (out of 30) patients, details of them belonging to whom were not available. Hence, we excluded this study from our analysis. Out of 5 patients from Clavel et $\mathrm{al}^{10}$ study, we could not include any case. Three cases were operated based on angiography (without CT), whereas the other two cases who were having preoperative CT were operated in less than 14 days of injury.

Analysis of 43 cases available in the literature operated $\geq 14$ days after injury showed that history of injury was present in $42(97.7 \%)$ cases $(n=43)$. The age range of the study population was 4 to 57 years, with most patients being less than 30 years of age. Majority (79\%) of the patients were males, whereas $21 \%$ were females. Headache $(74.4 \%)$ was the most common presenting symptom, followed by limb weakness (20.9\%) and behavior disturbances (9.3\%). 


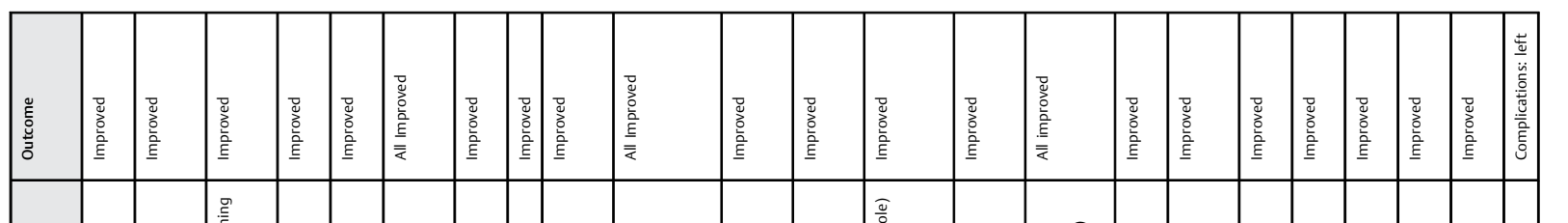

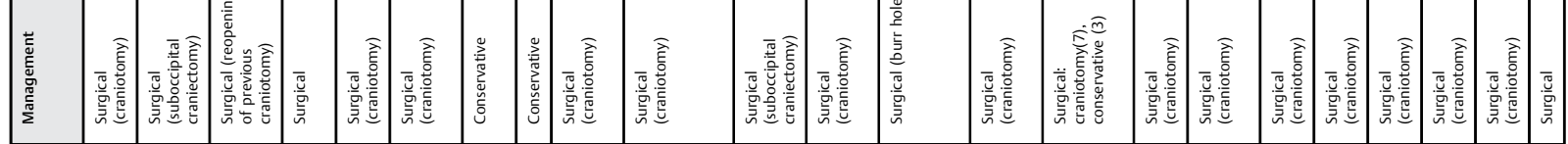

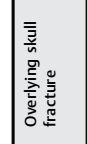
箁高

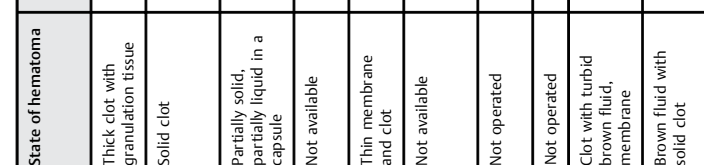

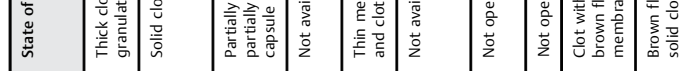

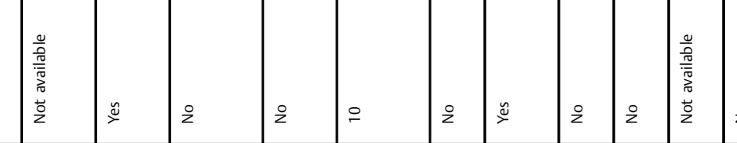

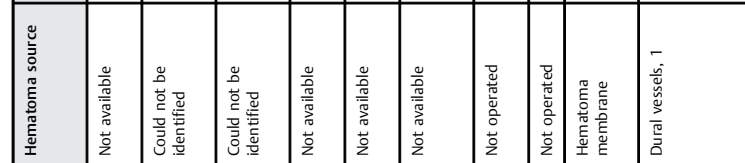

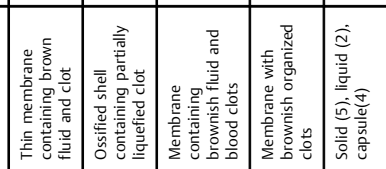

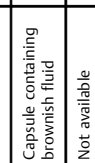

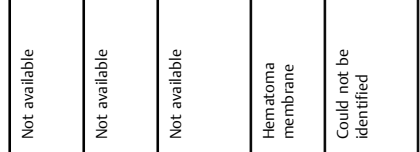

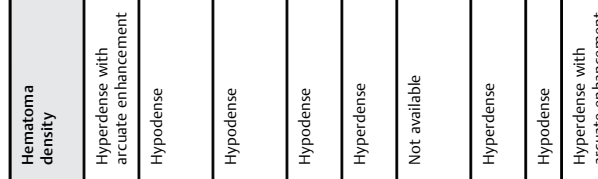

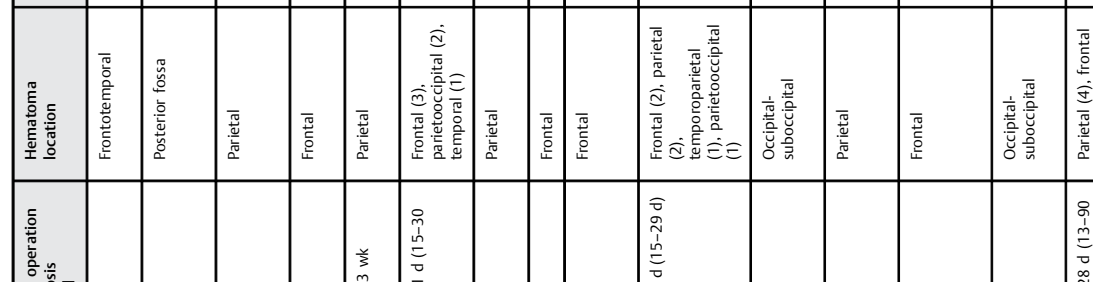

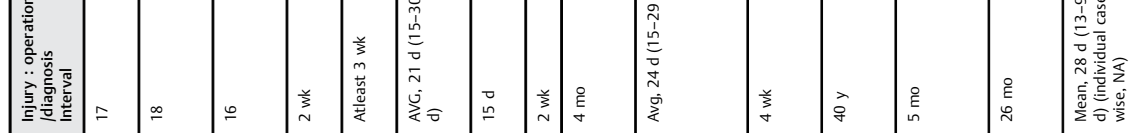

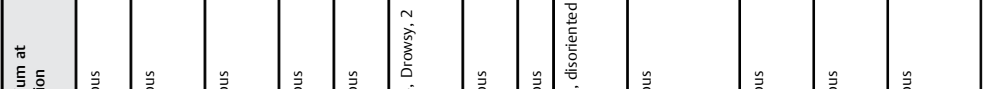

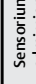

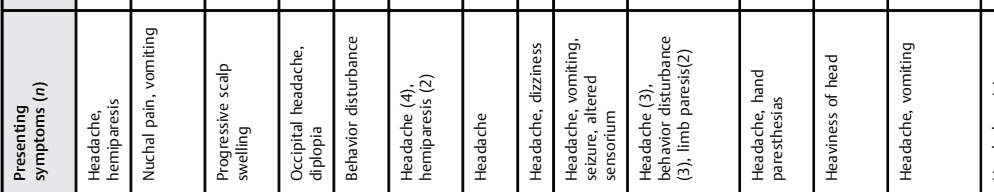

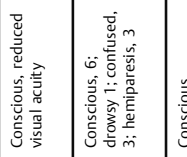

๙

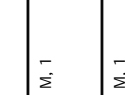

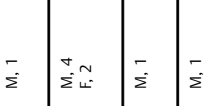

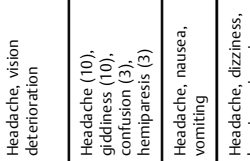

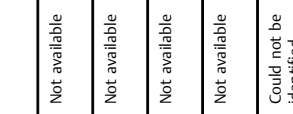

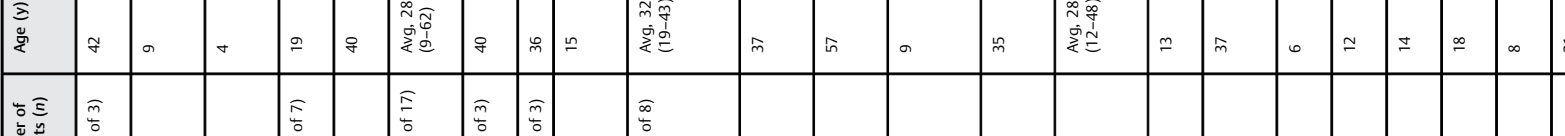

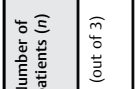

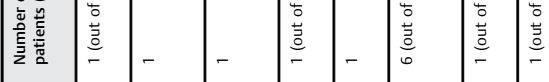

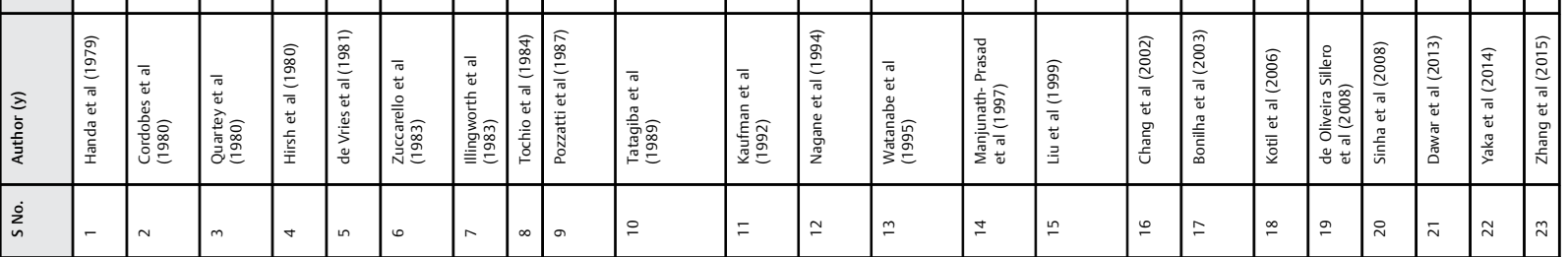




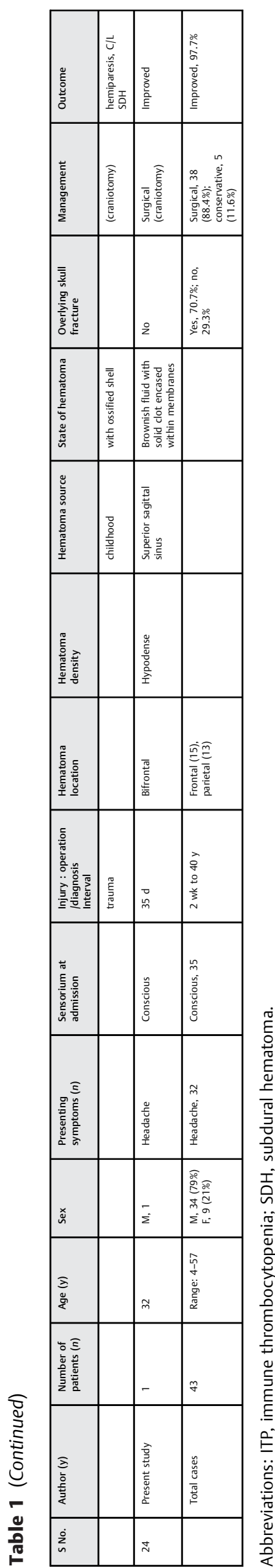

Majority (81.4\%) of the patients were conscious/alert, whereas $18.6 \%$ patients were in unconscious state at the time of surgery. Frontal (34.9\%) and parietal (30.2\%) were the most common locations of CEDH. Overlying skull fracture was present in $70.7 \%$ of patients. Majority (88.4\%) of them underwent surgical evacuation (craniotomy/craniectomy) of hematoma, whereas $11.6 \%$ of them were managed conservatively. Majority (97.7\%) of them showed satisfactory outcome and improved with surgical/conservative management. Only one patient of Zhang et $\mathrm{al}^{11}$ who was having spontaneous gigantic ossified right frontoparietal CEDH developed left hemiplegia after evacuation of hematoma. Injury to operation/detection interval varied from 2 weeks to as late as 40 years in our analysis. More than $50 \%$ of the patients who required surgical intervention did so within 1 month of injury, though delayed surgery as late as 40 years has been reported. All the 5 patients who were managed conservatively got cured (showed complete resolution of hematoma on follow-up CT) by 6 to 8 weeks after injury and did not show any delayed deterioration or hematoma enlargement.

\section{Discussion}

Development of noninvasive neuroimaging (CT) in 1972 brought a revolutionary change in management of head injury by reducing detection time; thus changing the clinical course of the injury and improving outcome compared with pre-CT era. ${ }^{12}$

The larger extradural hematomas (volume $>30 \mathrm{cc}$, midline shift $>5 \mathrm{~mm}$, and clot thickness $>15 \mathrm{~mm}$ ) usually being symptomatic get evacuated early by craniotomy, whereas the smaller asymptomatic ones are managed conservatively with close observation. ${ }^{13,14}$ The extradural hematoma, if not evacuated surgically may either get absorbed and disappear in 3 to 15 weeks, ${ }^{15}$ or get encapsulated and persist, ${ }^{16}$ or get calcified, ${ }^{17}$ or may enlarge due to repeated oozing from inner table of skull, dural surface vessels, or from hematoma membranes. ${ }^{17-19}$

Resorption process of extradural hematomas is likely to be similar ${ }^{12,20}$ but slower and less efficient ${ }^{21}$ than subdural hematomas due to presence of lesser absorptive surfaces (fibrous dura mater on one side and bone on the other side). It involves development of inner and outer membranes and liquefaction of the clot leading to accumulation of browncolored fluid between the inner and outer membranes. Neomembrane/capsule formed in CEDH histopathologically resembles the chronic subdural membrane. ${ }^{14,20,22}$ Liquefaction of clot occurs in a predictable time course and can be identified by CT scan. ${ }^{12}$ However, liquefaction of CEDH is never complete, and it would not be very accurate to assess the age of hematoma on the basis of its consistency found intraoperatively. ${ }^{23}$

Mere absence of symptoms during follow-up in a conservatively managed EDH patient does not indicate "cure" of an EDH. An EDH should be considered as "cured" only after disappearance of the membranes and hematoma on follow-up CT. ${ }^{24,25}$ 
Table 2 List of CEDH studies not included in the analysis

\begin{tabular}{|c|c|c|c|}
\hline S No. & Author (year of publication) & Cases $(n)$ & Reason for not including in the analysis \\
\hline 1 & Gurdjian et $\mathrm{al}^{38}(1938)$ & 1 & No CT \\
\hline 2 & Jackson et al ${ }^{16}(1950)$ & 1 & No CT \\
\hline 3 & King et al ${ }^{39}(1952)$ & 8 & No CT \\
\hline 4 & Trowbridge et al ${ }^{40}$ (1954) & 2 & $\begin{array}{l}\text { No CT; injury: operation interval was }<14 \mathrm{~d} \text { in } \\
\text { both cases }\end{array}$ \\
\hline 5 & Stevenson et a ${ }^{33}(1964)$ & 1 & No CT \\
\hline 6 & Sparacio et al ${ }^{2}(1972)$ & 9 & No CT \\
\hline 7 & Iwakuma et al ${ }^{28}(1973)$ & 21 & No CT \\
\hline 8 & Punt et al ${ }^{41}(1978)$ & 1 & No CT \\
\hline 9 & Pozzati et al ${ }^{9}(1980)$ & 30 & $\begin{array}{l}\text { Out of } 30 \text { patients; } 20 \text { were operated in }<14 \\
\text { d after injury, and only } 10 \text { were operated }>14 \\
\text { d after injury. But case-specific data of these } \\
10 \text { patients was not available. }\end{array}$ \\
\hline 10 & Mathur et al ${ }^{21}(1980)$ & 1 & No CT \\
\hline 11 & Bullock et $\mathrm{al}^{27}(1982)$ & 35 & $\begin{array}{l}\text { Injury: operation interval was } \geq 7 \mathrm{~d} \text {. Case- } \\
\text { specific data of patients operated }>14 \mathrm{~d} \text { after } \\
\text { injury was not available }\end{array}$ \\
\hline 12 & Clavel et al ${ }^{10}(1982)$ & 5 & $\begin{array}{l}\text { Injury: operation interval was }<14 \mathrm{~d} \text { in } 2 \\
\text { patients having CT; remaining } 3 \text { patients did } \\
\text { not have a preoperative CT scan. }\end{array}$ \\
\hline 13 & Jawahar et al ${ }^{42}(1985)$ & 1 & No CT \\
\hline 14 & Is et $\mathrm{al}^{29}(2006)$ & 2 & Injury: operation interval was $48 \mathrm{~h}$ \\
\hline
\end{tabular}

Abbreviations: $\mathrm{CEDH}$, chronic extradural hematoma; $\mathrm{CT}$, computed tomography.

A disease can be labeled as "chronic" if its signs and symptoms develop slowly over a lengthy period of time. ${ }^{2} \mathrm{~A}$ subdural hematoma identified more than 21 days after injury is called chronic subdural hematoma. However, there is no consensus on the precise time-based definition of chronic epidural hematoma; with injury to detection/ operation time gap varying from 48 hours to 2 weeks in different studies available in literature. ${ }^{14,26}$ Sparacio et $\mathrm{al}^{2}$ defined $\mathrm{CEDH}$ as those extradural hematomas operated $>48$ hours after injury, and Clavel et al ${ }^{10}$ defined CEDH as EDH diagnosed $>72$ hours after injury; thus excluding classic acute cases likely to deteriorate dramatically within few hours after injury. Bullock et $\mathrm{al}^{27}$ defined CEDH as the EDH with injury to operation interval of atleast 7 days. However, Iwakuma et $\mathrm{al}^{28}$ adopted anatomopathologic criterion defining CEDH as those EDH operated $>13$ days after injury, and was similar to that of Zuccarello et al. ${ }^{3}$ Pozzati et $\mathrm{al}^{9}$ have suggested to use the term "chronic" only for those EDH with onset of symptoms extended over 1 month after injury. Recently, based on hemoglobin breakdown products on MRI, Bradley et al ${ }^{1}$ have defined CEDH as extradural hematomas identified more than 14 days after head injury. This definition seems to be more scientific, recent, and evidence based.

The reported incidence of $\mathrm{CEDH}$ in the literature ranges from 3.9 to $30 \%$ of all epidural hematomas. It occurs more commonly in the younger ( $<40$ years) age groups. ${ }^{14,29}$ Some of them are identified incidentally, whereas others are diagnosed while investigating for persistent and/or progressive symptoms like headache, dizziness, nausea, vomiting, memory impairment, hemiparesis, and disturbance of consciousness. Some are initially small but may enlarge slowly and present with delayed neurological deterioration due to persistent slow and active bleeding. Dawar et al $^{19}$ have reported a case of double acute EDH which though initially managed conservatively (good sensorium) required $\mathrm{CEDH}$ evacuation 20 days after injury for management of sudden onset altered sensorium 20 days after injury.

The pathogenetic mechanisms that can be invoked to explain chronicity in extra-axial hematomas include associated skull fractures, frontally located hematomas, age-related diffuse cerebral atrophy, venous source of bleeding, and traumatic A-V fistulae of meningeal vessels. ${ }^{30}$

The clinical manifestations are often subtle, and the neurological status is usually satisfactory. ${ }^{14}$ The plain CT head shows a biconvex extra-axial collection with a hypodense central core surrounded by a hyperdense enhancing margin with or without calcification at the dura mater-hematoma junction and mass affect. ${ }^{14}$ On gross examination, CEDH may appear as an organized solid hematoma or brown fluid with partially liquefied clot contained within an organized and vascularized membrane. $^{14,22}$ 
Symptomatic $\mathrm{CEDH}$ requires surgical evacuation (the earlier, the better) and has an excellent outcome. However, spontaneous resolution may be expected in patients with no or mild symptoms, normal neurological status, and a smallsized CEDH without any mass effect. A watchful wait may be appropriate in such cases, but implies a high cost of serial scans and long hospitalization. ${ }^{26,31}$ If CEDH is observed not to be naturally absorbed during serial scans on follow-up; surgical evacuation should be considered, even if the patient's condition is good, because of the likelihood of calcification/ossification. ${ }^{22}$ Literature review showing many case reports of calcified/ossified CEDH in children (no calcium metabolism abnormality) suggests that conservative management of borderline-sized acute EDH, especially in children, might not be the best treatment as they may be at risk of requiring delayed craniotomy ${ }^{17,32}$ for calcified/ossified CEDH causing skull deformity. ${ }^{17}$ Kotil et $\mathrm{al}^{32}$ Tatagiba et $\mathrm{al}^{7}{ }^{7}$ and de Oliveira Sillero et $\mathrm{al}^{26}$ have recommended surgery (craniotomy and excision) for CEDH especially with calcification/ossification, even if patient is asymptomatic due to the risk of delayed deterioration.

Once the clot gets liquefied, it may be drained through minimally invasive procedures like twist drill or burr holes; but the long time required for this clot liquefaction may keep the patient symptomatic for long unnecessarily. Moreover, twist drill/burr holes might drain the liquid portion adequately, but shall be inadequate for removing the solid clot portion of CEDH and hence are not recommended. Also, recurrence due to rebleeding from inner and outer hematoma membranes is a likely complication on followup especially if hematoma is drained by minimally invasive techniques (burr hole or twist drill) only.

Our case is unique as this is a well-documented (MR venography proven) case report of such a large CEDH associated with sinus injury without an overlying bone fracture. In the pre-CT era, Stevenson et $\mathrm{al}^{33}$ and Gurdjian et $\mathrm{al}^{34}$ have reviewed the cases of extradural hematomas associated with dural sinus injury. Venous sinus involvement used to be documented by sinus displacement away from inner table of the skull on venous phase of angiogram in those times. ${ }^{33}$ Besides the $\mathrm{CEDH}$, raised intracranial pressure in our patient might have been due to of the superior sagittal sinus obliteration leading to impaired venous return and cerebrospinal fluid absorption. Watchful expectancy of such large extradural hematomas should be deferred and a prompt early surgical evacuation should be performed that prevents any possible neurological deterioration later in the course of the disease.

With the advancement of surgical techniques, neuroanesthesia, and intensive care units, it does not seem to be judicious to wait for such large acute hematomas to become chronic and then undergo minimally invasive surgery at a later date. Any intraoperative bleeding from major venous sinuses can be managed easily using various hemostats like surgical, gelfoam etc., and maneuvers such as head end elevation, lowering of blood pressure, etc. Instead of bifrontal craniotomy, bilateral frontal craniotomy leaving in situ a bone strip overlying superior sagittal sinus may be done by relatively inexperienced and young neurosurgeons to avoid difficult-to-manage sinus bleeds. Dural hitches can also be tied across this bone strip to control the sinus bleed. Hence, sinus injury associated larger extradural hematomas should be evacuated at the earliest to ensure a safe and predictable outcome. Cost of surgical treatment of such large acute extradural hematomas is likely to be equal to the cumulative cost of long conservative or delayed surgical management (serial CTs, in-hospital stay for observation, and loss of working hours of patient and caregiver) with an additional advantage of improving the quality of the patient's life at the earliest with an acceptable surgical risk and making the outcome more predictable.

Analysis of 43 patients in the literature operated 314 days after injury showed that history of injury was present in 42 (97.7\%) patients $(n=43)$. Zhang et al (2015) have reported a case of nontraumatic CEDH secondary to blood dyscrasias (thrombocytopenic purpura). ${ }^{11}$ The age range of study population was 4 to 57 years, with majority of patients being less than 30 years of age. CEDH tends to be more prevelent in young adults, below 30 years of age. ${ }^{6}$ Like acute $\mathrm{EDH}, \mathrm{CEDH}$ is more commonly seen in the young population due to the ease with which dura is stripped off the inner table of skull following the impact, compared with infants and elderly. ${ }^{2}$ The majority (79\%) were males, whereas $21 \%$ were females. As described in literature ${ }^{35}$, preponderence of young males was seen as they are more exposed to manual work and thus more physical injuries. Headache (74.4\%) was the most common presenting symptom, followed by limb weakness (20.9\%) and behavior disturbances (9.3\%). One patient of Nagane et $\mathrm{al}^{35}$ presented with heaviness of head (not headache). One patient each of Quartey et $\mathrm{al}^{30}$ (who had undergone craniotomy previously for arachnoid cyst) and Yaka et $\mathrm{al}^{36}$ presented with progressive scalp swelling. Majority (81.4\%) were conscious/alert, whereas $18.6 \%$ patients were either drowsy or in altered sensorium at the time of surgery. Slow evolution of hematoma gives time to the brain for adjustments, thus leading to paucity of neurological findings. ${ }^{3}$ In Tatagiba et $\mathrm{al}^{7}$ study, the most common symptom was headache and all of them were alert at the time of operation. In Bullock et $\mathrm{al}^{27}$ study, deteriorating level of consciousness and lateralizing limb weakness were the most common presenting features. Frontal (34.9\%) and parietal (30.2\%) were the more common locations of CEDH in our analysis. Tatagiba et $\mathrm{al}^{7}$ have reported topographical preponderance of $\mathrm{CEDH}$ in frontal and parietal regions in their study. Slow clinical development and no impairment of consciousness are the features of frontal EDHs. ${ }^{28}$ Neurological symptoms and signs may be vague and of late onset in EDHs located outside middle cranial fossa, and thus are difficult to suspect clinically. ${ }^{5}$ Many of the chronic lesions were not temporal. ${ }^{28} \mathrm{CEDH}$ confined to temporal fossa cause uncal herniation earlier and at a small critical volume of clot than clots located elsewhere. Frontal EDHs are less likely to cause the lethal medial temporal lobe induced brainstem compression, and thus manifest late. ${ }^{20}$ The classical presentation of EDH (transient unconsciuousness, followed 
by lucid interval, followed by rapidly decline in consciousness with dilated pupil and contralateral hemiparesis) represents one extreme end of the spectrum, ${ }^{27}$ and was not seen in any of the cases reviewed here. Majority of the patients presented with minimal symptoms and signs, appear to lie on the opposite end of the spectrum. Overlying skull fracture was present in $70.7 \%$ of patients. Patient may remain asymptomatic due to the spontaneous decompression of extradural hematoma into subgaleal space through an overlying skull fracture (pressure gradient mechanism). ${ }^{36}$ In Tatagiba et $\mathrm{al}^{7}$ study, skull fracture was frequently but not always found (67\%) on $\mathrm{X}$-rays in their study. EDHs underlying a fracture traversing a major dural vessel or venous sinus are more likely to enlarge due to continuous low pressure bleed. ${ }^{37}$ There was no description in any paper suggesting the fracture to be compound. More than three-fourth of CEDHs included in the analysis were hypodense on plain CT scan. In Tatagiba et $\mathrm{al}^{7}$ study, hematoma was hypodense on CT in all 6 patients, but no dural calcification was seen; and rim enhancement of hematoma on contrast was seen in majority of them. Majority (88.4\%) underwent surgical evacuation (craniotomy, craniectomy) of hematoma, whereas $11.6 \%$ of them were managed conservatively. Majority (97.7\%) of them showed satisfactory outcome and improved with surgical/conservative management. Only one patient of Zhang et $\mathrm{al}^{11}$ who was having spontaneous gigantic ossified right frontoparietal CEDH developed left hemiplegia after evacuation of hematoma. Injury to operation/detection interval varied from 2 weeks to 40 years in our analysis. More than $50 \%$ of the patients who required surgical intervention did so within 1 month of injury, though delayed surgery as late as 40 years has been needed. All the 5 patients who were managed conservatively got cured (showed complete resolution of hematoma on follow-up (T) by 6 to 8 weeks after injury and did not show any delayed deterioration or hematoma enlargement. In Pang et $\mathrm{al}^{20}$ study, complete resorption of medium to large sized EDH (managed conservatively) occurred between 4 to 7 th week following injury. Illingworth et $\mathrm{al}^{8}$ managed 3 patients of EDH conservatively and serial CT scans showed resolution of hematoma by 4 to 6 weeks. Majority of CEDH had not liquefied completely and were found to have brown fluid mixed with clots during surgery in our analysis. This is similar to that described in literature. In Tatagiba et $\mathrm{al}^{7}$ study of 8 patients, hematoma was solid in 2 patients and fluid with an organized solid clot in 6 patients. In contrast to chronic subdural hematoma which can be evacuated by burr holes, retention of solid clot is a characteristic of CEDH and thus it is difficult to evacuate a CEDH by burr holes. ${ }^{23,35}$ Craniotomy should be preffered for CEDH evacuation as simple burr holes might not be adequate for removing the solid clot portion. ${ }^{2}$ None of the cases showed active arterial bleeding as CEDH source during surgery. Also, it is much easier to detect a high pressure bleeding arterial source during surgery than identifying other low pressure sources of bleed. ${ }^{23}$ Pozzati et $\mathrm{al}^{9}$ identified the combined lowtension forces (venous, dural, or diploid) as the source of
CEDH. Among studies of pre-CT era, Sparacio et $\mathrm{al}^{2}$ operated 9 cases and found no point of active bleeding in any of them. Similarly, Iwakuma et $\mathrm{al}^{28}$ could not identify a bleeding point during surgery in 13 out of 21 patients, and assumed bleeding to be of venous origin. Low pressure of bleeding allows time for brain and cerebrospinal fluid to accommodate the slowly developing extradural hematoma, leading to the patient being relatively symptom-free compared with same-sized EDH developing rapidly (no intracanial compensation). ${ }^{7}$ Nearly all cases (except the single patient of Zhang et $\mathrm{al}^{11}$ ) had good outcome after surgery. Thus, CEDH if managed appropriately, leads to very low morbidity and mortality.

\section{Conclusion}

Any person with a history of impact to head and who, even if alert, is having mild persistant symptoms and/or signs should be suspected to have CEDH until proved otherwise by neuroimaging. Outcome of surgical management of symptomatic CEDHs is usually excellent, though smaller ones can be managed conservatively. Even sinus injury associated large extradural hematomas should be surgically evacuated at the earliest to ensure an early, safe, and predictable outcome. Likelihood of massive intraoperative bleeding from venous sinuses should not be a deterrent for surgery as such bleeding can be easily controlled using hemostats and other intraoperative maneuvers.

\section{Funding}

None.

Conflict of Interest

None.

\section{References}

1 Bradley WG Jr. Hemorrhage and hemorrhagic infections in the brain. Neuroimaging Clin N Am 1994;4(4):707-732

2 Sparacio RR, Khatib R, Chiu J, Cook AW. Chronic epidural hematoma. J Trauma 1972;12(5):435-439

3 Zuccarello M, Fiore DL, Pardatscher K, Trincia G, Andrioli GC. Chronic extradural haematomas. Acta Neurochir (Wien) 1983;67(1-2):57-66

4 Handa J, Handa H, Nakano Y. Rim enhancement in computed tomography with chronic epidural hematoma. Surg Neurol 1979; 11(3):217-220

5 Hirsh LF. Chronic epidural hematomas. Neurosurgery 1980;6(5): 508-512

6 Tochio H, Waga S, Tashiro H, Takeuchi T, Miyazaki M. Spontaneous resolution of chronic epidural hematomas: report of three cases. Neurosurgery 1984;15(1):96-100

7 Tatagiba M, Sepehrnia A, el Azm M, Samii M. Chronic epidural hematoma-report on eight cases and review of the literature. Surg Neurol 1989;32(6):453-458

8 Illingworth $\mathrm{R}$, Shawdon $\mathrm{H}$. Conservative management of intracranial extradural haematoma presenting late. J Neurol Neurosurg Psychiatry 1983;46(6):558-560 
9 Pozzati E, Frank F, Frank G, Gaist G. Subacute and chronic extradural hematomas: a study of 30 cases. J Trauma 1980;20(9):795-799

10 Clavel M, Onzain I, Gutierrez F. Chronic epidural haematomas. Acta Neurochir (Wien) 1982;66(1-2):71-81

11 Zhang W, Zhang W, Gao Z, Wang J. Gigantic ossified chronic epidural haematoma and contralateral postoperative subdural haematoma: a case report and literature review. Br J Neurosurg 2014;29(1):1-2

12 Kaufman HH, Herschberger J, Kopitnik T, McAllister P, Hogg J, Conner T. Chronic extradural haematomas: indications for surgery. Br J Neurosurg 1992;6(4):359-364

13 Bullock MR, Chesnut R, Ghajar J, et al; Surgical Management of Traumatic Brain Injury Author Group. Surgical management of acute epidural hematomas. Neurosurgery 2006;58(3, Suppl): S7-S15, discussion Si-iv

14 Liu Y, Wang Y, Song T, et al. Chronic epidural haematoma: a report of 10 cases and review of the literature. J Clin Neurosci 1999;6(5):412-415

15 Chen TY, Wong CW, Chang CN, et al. The expectant treatment of "asymptomatic" supratentorial epidural hematomas. Neurosurgery 1993;32(2):176-179, discussion 179

16 Jackson IJ, Speakman TJ. Chronic extradural hematoma. J Neurosurg 1950;7(5):444-447

17 Sinha S, Borkar S. Chronic calcified extradural hematoma in a child: case report and review of literature. Indian J Neurotrauma 2008;5(1):51-52

18 Watanabe T, Nakahara K, Miki Y, Shibui S, Takakura K, Nomura K. Chronic expanding epidural haematoma. Case report. Acta Neurochir (Wien) 1995;132(1-3):150-153

19 Dawar P, Phalak M, Sinha S, Sharma BS. Same side double chronic calcified epidural hematoma: case report and review of literature. Neurol India 2013;61(2):195-197

20 Pang D, Horton JA, Herron JM, Wilberger JE Jr, Vries JK. Nonsurgical management of extradural hematomas in children. J Neurosurg 1983;59(6):958-971

21 Mathur PPS, Dharker SR, Agarwal SK, Sharma M. Fluid chronic extradural haematoma. Surg Neurol 1980;14(1):81-82

22 Chang JH, Choi JY, Chang JW, Park YG, Kim TS, Chung SS. Chronic epidural hematoma with rapid ossification. Childs Nerv Syst 2002;18(12):712-716

23 Milo R, Razon N, Schiffer J. Delayed epidural hematoma. A review. Acta Neurochir (Wien) 1987;84(1-2):13-23

24 Manjunath-Prasad KS, Gupta SK, Khosla VK. Chronic extradural haematoma with delayed expansion. Br J Neurosurg 1997;11(1): 78-79

25 Pozzati E, Staffa G, Nuzzo G, Frank F. Late recurrence of bleeding in a chronic extradural hematoma. J Trauma 1987;27(5):579-580
26 de Oliveira Sillero R, Zanini MA, Gabarra RC. Large chronic epidural hematoma with calcification: a case report. J Trauma 2008;64(6):1619-1621, discussion 1621

27 Bullock R, van Dellen JR. Chronic extradural hematoma. Surg Neurol 1982;18(4):300-302

28 Iwakuma T, Brunngraber CV. Chronic extradural hematomas. A study of 21 cases. J Neurosurg 1973;38(4):488-493

29 Is M, Can A, Akgul MH. Chronic supra-and infratentorial epidural hematoma. Case report. Turk Neurosurg 2006;16(4): 212-213

30 Quartey GR, Gabriel YH, Tchang S. Chronic extradural hematoma presenting with subgaleal mass. Can J Neurol Sci 1980;7(1): 71-72

31 Bonilha L, Mattos JP, Borges WA, Fernandes YB, Andrioli MS, Borges G. Chronic epidural hematoma of the vertex. Clin Neurol Neurosurg 2003;106(1):69-73

32 Kotil K, Akçetin MA. Asymptomatic chronic ossified epidural hematoma in a child: a rare entity. Ulus Travma Acil Cerrahi Derg 2006;12(2):164-166

33 Stevenson GC, Brown HA, Hoyt WF. Chronic venous epidural hematoma at the vertex. J Neurosurg 1964;21:887-891

34 Gurdjian ES, Webster JE. Extradural hemorrhage. A collective review of the literature and a report of 30 cases of middle meningeal hemorrhage and 4 cases of dural sinus hemorrhage treated surgically. Int Abstr Surg 1942;75:206-220

35 Nagane M, Oyama H, Shibui S, Nomura K, Nakanishi Y, Kamiya M. Ossified and calcified epidural hematoma incidentally found 40 years after head injury: case report. Surg Neurol 1994;42(1): 65-69

36 Yaka E, Pekdemir M, Kama A, Sarısoy HT, Yılmaz S. Asymptomatic chronic epidural hematoma in a child as a result of extracranial decompression. J Emerg Med 2014;46(4):482-485

37 Knuckey NW, Gelbard S, Epstein MH. The management of "asymptomatic" epidural hematomas. A prospective study. J Neurosurg 1989;70(3):392-396

38 Gurdjian ES. Operative management of traumatic intracranial hemorrhage. Am J Surg 1938;40:596-610

39 King $A B$, Chambers JW. Delayed onset of symptoms due to extradural hematomas. Surgery 1952;31(6):839-844

40 Trowbridge WV, Porter RW, French JD. Chronic extradural hematomas. AMA Arch Surg 1954;69(6):824-830

41 Punt J. Chronic extradural hematoma presenting 33 years after penetrating cranial trauma. Case report. J Neurosurg 1978;49(1): 103-106

42 Jawahar G, Natarajan M. Chronic extradural haematoma. J Indian Med Assoc 1985;83(12):413-416, 416 